\title{
Organophosphate Ester Flame Retardant-Induced Acute Intoxications in Dogs
}

\author{
Andreas F. Lehner • Francisca Samsing • \\ Wilson K. Rumbeiha
}

Published online: 18 August 2010

(C) American College of Medical Toxicology 2010

\begin{abstract}
Introduction Flame retardants have wide industrial applications and are incorporated into articles found in automobiles and home environments, including seat cushions. These compounds differ widely chemically and in their toxic potential. We report here two cases involving dogs following ingestion of car seat cushions impregnated with organophosphate ester fire retardants.

Case Reports Two case reports are presented. Two adult American Pit Bull dogs were presented at an emergency clinic with acute signs of central nervous system excitation including seizures. The most severely affected dog died 15 min after presentation, while the less affected dog fully recovered following treatment. In the second case, both a German Shepherd and a Rottweiler were found dead in the morning after they were left in a car overnight. A comprehensive toxicological analysis of samples from both cases revealed the presence of significant amounts $(>2 \mathrm{ppm})$ of tris (2-chloroethyl)phosphate (TCEP) in stomach contents. This compound is a known inducer of epileptic seizures. Some other structurally related organophosphate ester compounds were found, and their role in the acute intoxications reported here is not known and remains to be determined.

Conclusion This is the first report linking acute deaths in dogs to the ingestion of car seat cushions found to contain
\end{abstract}

\footnotetext{
A. F. Lehner $(\bowtie) \cdot$ W. K. Rumbeiha

Toxicology Section, Diagnostic Center for Population and Animal Health (DCPAH), Michigan State University,

4125 Beaumont Rd,

East Lansing, MI 48910, USA

e-mail: LehnerA@dcpah.msu.edu

F. Samsing

Centro de Investigaciones Ecotoxicológicos Universidad Mayor

(CIE MAYOR), Universidad Mayor,

Santiago, Chile

large amounts of TCEP, an organophosphate ester compound. It is highly likely that this compound caused death through its known seizure-inducing activity.

Keywords Organophosphorus flame retardants · Seizures . Tris(2-chloroethyl) phosphate (TCEP) .

Tris(1-chloro-2-propyl) phosphate (TCPP) · Dogs

\section{Introduction}

Flame retardants (FRs) are chemicals added to polymeric materials to inhibit or reduce the spread of fire. FRs may be physically blended with or chemically bonded to the host polymer [1,2]. The term "flame retardant" represents a class of use and not a class of chemical structure [1], and FR chemicals can be inorganic or organic compounds, the latter being either halogen- and/or phosphorus containing. Bromine- and chlorine-containing compounds are the only halogenated compounds with commercial significance; however, brominated FRs (BFRs) are much more widely used because of their higher efficacy [1].

Polybrominated diphenyl ethers (PBDEs) are principal examples of BFRs. The toxicological effects of PBDEs vary inversely with the degree of bromination such that the toxicity of the tetra- through deca-brominated diphenyl ethers declines with increasing levels of bromination $[1,3]$. They are a potential health risk for both humans and animals because they persist in the environment, accumulate in the food chain, and have known toxic effects [4]. Penta-brominated diphenyl ethers appear to be more toxic after oral administration than octaand deca-brominated diphenyl ethers, as they cause clear signs of toxicity and mortality [5]. Studies with PBDEs have reported hepatotoxicity, embryotoxicity, neurotoxic- 
ity, and thyroid toxicity as well as maternal toxicity during gestation [4-6]. Most of these effects, however, follow chronic exposure to these compounds.

Among the phosphorus-containing FRs, organophosphate esters (OPEs), particularly the triesters, are the most commonly used $[2,7]$, and their usage has increased in the past years due to the ban in many countries of BFRs. Organophosphate esters are heterogeneous in their chemical, structural, and physical properties, and thus in their applications. These are used as FRs as well as plasticizers in a wide variety of products, including varnishes, rigid and flexible polyurethane foams, upholstery, and textiles [8].

Organophosphate pesticides are known to have various physiological effects during acute intoxication, including inhibition of central nervous system (CNS) acetylcholinesterase in mammals $[9,10]$, increased respiration amplitude, decreased blood pressure and cardiac output in cats exposed to para-oxon [11] and miosis, urination, diarrhea, diaphoresis, lacrimation, excitation of the CNS, salivation, and consciousness disturbance in humans [12]. On the other hand, the acute toxicity of non-halogenated OPE FRs is relatively unexplored. Poisoning with lethal doses of tributoxyethyl-phosphate (TBOP) in rats is characterized by anticholinesterase activity with a significant reduction in caudal nerve conduction velocity. Light and electron microscopic exam revealed degenerative changes in myelinated and unmyelinated fibers [13]. Signs of intoxication in guinea pigs include adynamia, ataxia, clonic-tonic spasms, disturbance of the rhythm and rate of respiration, salivation and tremor [13], muscular flaccidity, and loss of reflexes [14]. TBOP administered in a feeding study to rats induced tremors, lacrimation, and increased frequency of urination, particularly in females; degeneration of myelin sheaths was accompanied by swelling of axons in nerve fibers as evidence of neurotoxicity [15]. High doses led to suppression of weight gain and increase in serum amylase in another study [16]. Study of TBOP and tributyl phosphate and dibutylphenyl phosphate in chickens resulted in delayed neurotoxicity following chronic exposure; TBOP caused $45 \%$ reduction in brain acetylcholinesterase enzyme activity [17]. Other effects of TBOP included mild changes in the liver, focal myocarditis, and hemolysis $[18,19]$.

The chlorinated organophosphate triesters such as tris (2-chloroethyl) phosphate (TCEP) and tris(1-chloro-2propyl) phosphate (TCPP) are OPEs that share structural features with halogenated FRs, specifically chlorinated FRs, which are employed in consumer articles for indoor use such as rigid and flexible polyurethane foams and thus are nearly ubiquitous [2]. These compounds are readily found in indoor environments, to the extent that they were found in $60-90 \%$ of indoor dust samples in one study [20]. Few data are available about the toxicity of these compounds [7, 21], and existing studies are mainly in laboratory animals [6]. Studies in rodents indicate that TCEP is not only neurotoxic but may also be a reproductive toxicant, and possibly a carcinogen [22-24]. Organophosphate esters are also reported to have hemolytic effects [18]. Clinical signs of TCEP toxicity in rodents include piloerection, increased salivation, hunched posture, abnormal gait, lethargy, labored respiration, ptosis, and convulsions [24]. It is known that tris(1,3-dichloro-2-propyl) phosphate is absorbed through human skin [25], which means that the addition of certain OPE FRs to fabrics could result in dermal exposure to consumers as well as oral exposure to young children [25].

Studies concerning acute toxicity in humans and domestic animals for both chlorinated and nonhalogenated OPEs are largely lacking. We report here two case reports in dogs involving acute flame retardant intoxications.

\section{Case Reports}

\section{Case Report No. 1}

Two adult American Pit Bull dogs arrived at an emergency clinic with acute signs of central nervous system excitation. The most severely affected dog, a castrated male, presented with seizures, had a temperature of $110^{\circ} \mathrm{F}$ (normal 99.5$102.5^{\circ} \mathrm{F}$ ), and was cyanotic. The second dog was a female which presented with similar but milder clinical signs. Both dogs were treated symptomatically for seizures using pentobarbital. The most severely affected dog died $15 \mathrm{~min}$ after presentation, while the less affected dog fully recovered following hospitalization and treatment with activated charcoal, atropine, and fluids.

Necropsy of the deceased dog revealed a frothy brown fluid in the stomach. Lungs were edematous. The stomach contents were submitted to the Michigan State University Diagnostic Center for Population and Animal Health (DCPAH) in East Lansing, MI, USA for a toxicology workup. Toxic differentials included the more common causes of central nervous system excitation, including strychnine, organochlorinated insecticides, metaldehyde, organophosphorus and carbamate pesticides, methylxanthines, bromethalin, and tremorgenic mycotoxins (penitrem A and roquefortine). Stomach contents tested negative for strychnine, bromethalin, roquefortine, and penitrem $\mathrm{A}$; these compounds are analyzed concurrently in a convulsant panel that uses thin-layer chromatography with gas chromatography/mass spectrometry (GC/MS) and liquid chromatography/mass spectrometry 
confirmations of any positives. Stomach contents were further subjected to GC/MS qualitative analysis. Of the compounds on the initial list of differentials, strychnine, organochlorinated pesticides, metaldehyde, organophosphorus and carbamate pesticides, and methylxanthines were eliminated as negative by GC/MS analysis. GC/MS also eliminated less common causes of CNS excitation that are readily detected by this method, such as drugs of abuse (e.g., amphetamines), certain plant toxins (such as tremetone, aesculin, or gamma-coniceine), and other pesticides such as pyrethroid insecticides. However, the GC/MS screen disclosed a large amount of TCEP (Fig. 1) that exceeded the peak area of our internal standard diphenylamine included in the sample at $2 \mu \mathrm{g} / \mathrm{ml}$, suggesting that it was present in similar amounts or greater. A detailed mass spectrometric library match for this principal component is shown in Fig. 2. A search of the home environment revealed that the dogs had torn apart and chewed on cushions of an old car in the garage. A GC/MS analysis of the cushion samples confirmed the presence of large amounts of TCEP.
Case Report No. 2

A 9-year-old 60-lb. female German Shepherd dog was found dead in a closed vehicle, in addition to a dead 70-1b. Rottweiler. Both dogs had struggled to get out and in the process had chewed on the car seats and dashboard. Nasal hemorrhage was evident in the German Shepherd. There were two differentials in this case, heat stroke [26] or acute intoxication. Poisoning was most strongly suspected, owing to the rapid progression of this case as evidenced by both dogs being in full health at $11 \mathrm{PM}$ and being found dead by 9 AM the next day. Necropsy of the deceased German Shepherd revealed that the stomach contained dog food, seat foam, pieces of steak, and little or no fluid. Kidneys appeared normal in size but were dark in color, suggesting congestion. The renal capsule was easily removed, and upon dissection, the corticomedullary junction was congested and not clearly delineated, indicating possible kidney injury. The urinary bladder was full, and the urine appeared normal. The liver was congested and dark colored. No free fluid was noted in the thoracic cavity.
Fig. 1 GC/MS of DCPAH case no. 1 stomach contents $[t o p]$ in comparison with a reference standard of tris(2-chloroethyl)phosphate (TCEP) [bottom]. In addition to TCEP, pentobarbital (12.90 $\mathrm{min})$ and a significant peak of dibutyl phthalate $(14.91 \mathrm{~min})$ were also found

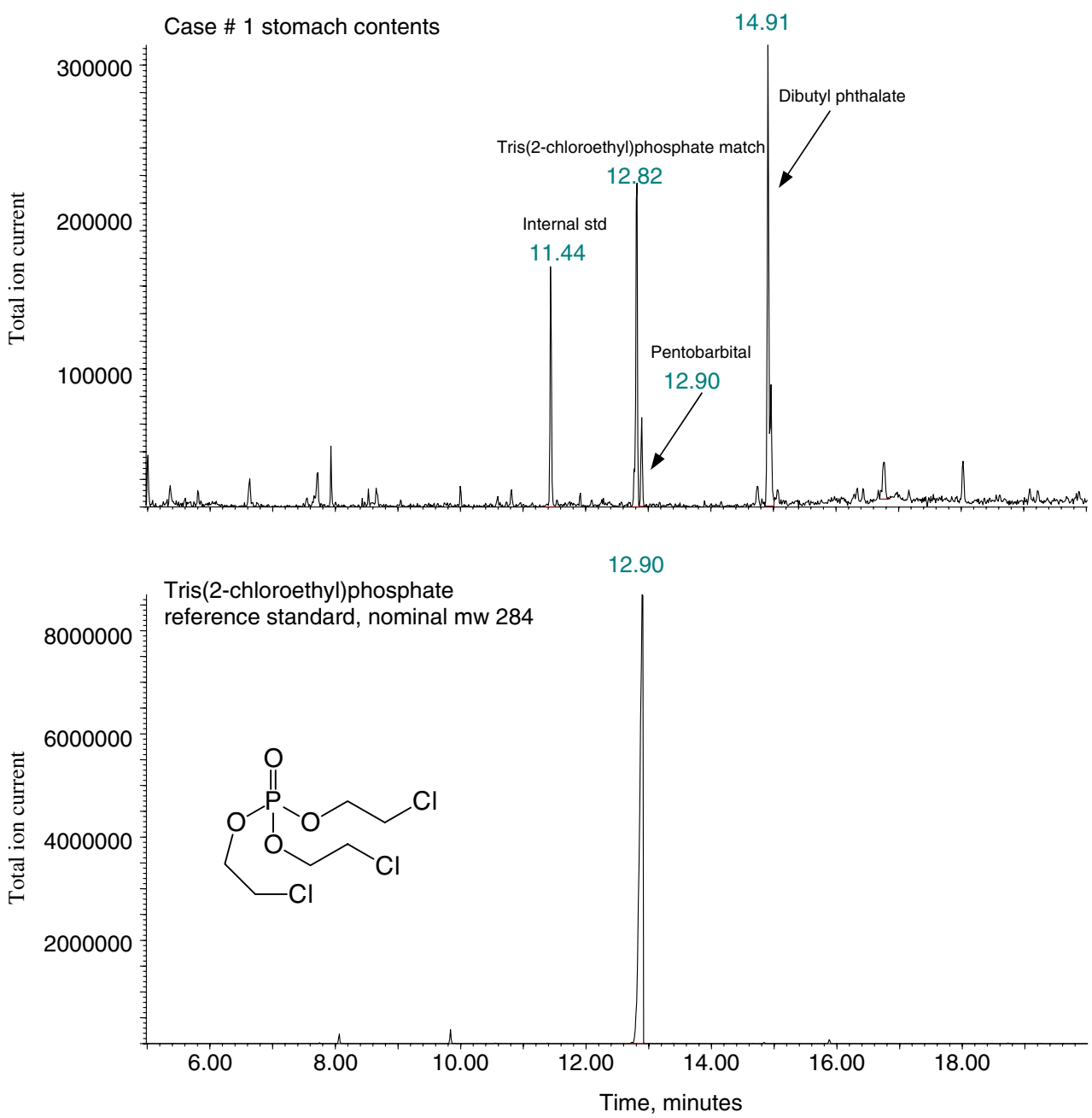


Fig. 2 Mass spectrum of principal component found in case no. 1 [top] in comparison with that of the tris (2-chloroethyl)phosphate standard [bottom]. Identities of principal fragments are labeled, as obtained by analysis with Mass Spec Calculator Pro software (ChemSW, Inc., Fairfield, CA, USA)
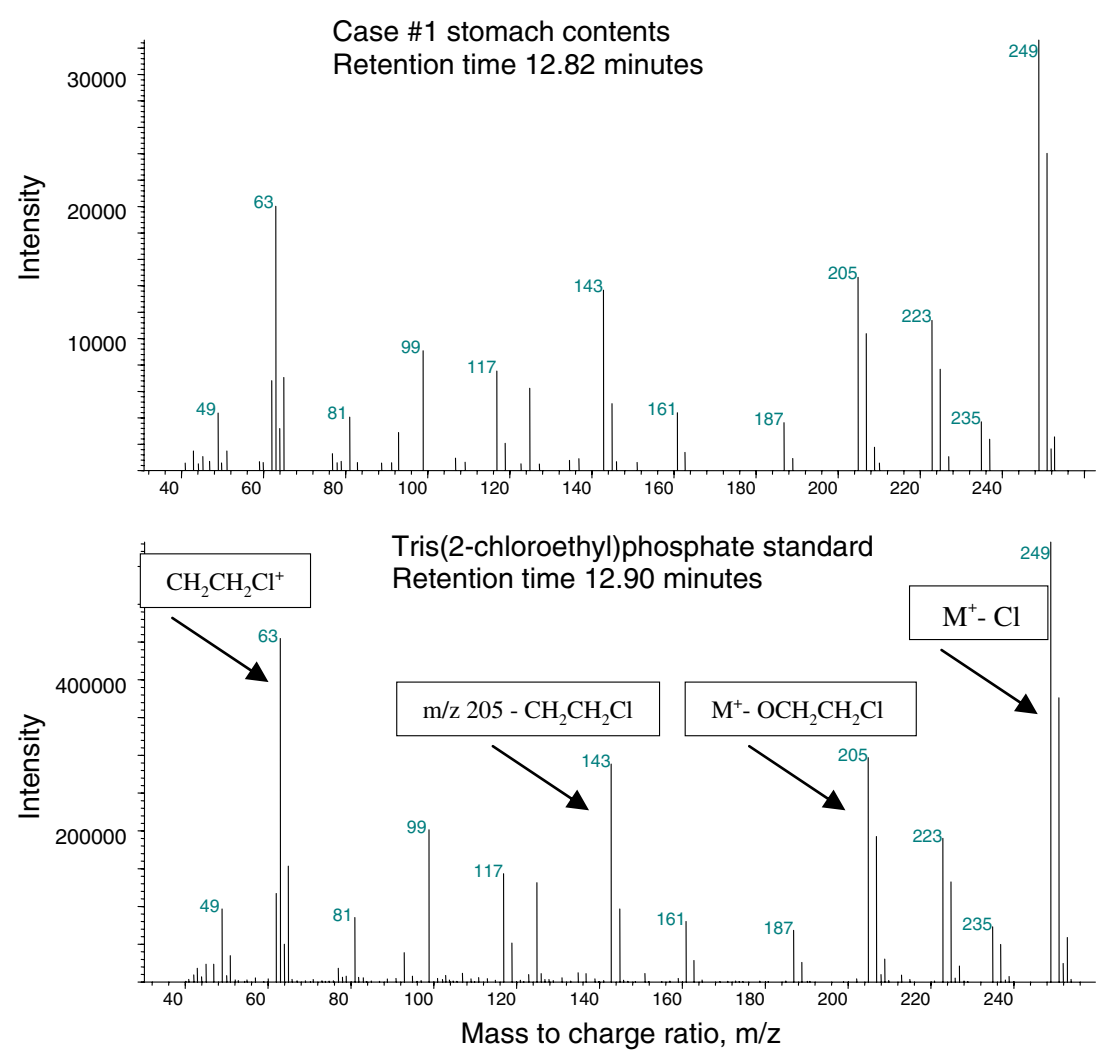

The lungs were congested and dark in appearance. Stomach contents were submitted to the Michigan State University DCPAH laboratory for toxicological analysis. The list of toxic differentials included flame retardant intoxication and common causes of peracute or acute death such as cyanide poisoning and organophosphorus or carbamate pesticide intoxication. Consequently, samples of stomach content were analyzed by GC/MS for organic toxicants (results summarized in Table 1). Concur- rent tests included analyses for ethylene glycol by gas chromatography/flame ionization detection; heavy metals such as arsenic, lead, mercury, and thallium by inductively coupled plasma (ICP-AES); and cyanide using a color-generating derivative measured spectrophotometrically [27]. Anticoagulant poisoning was included as a differential because of nasal bleeding observed in one dog. Besides stomach contents, whole blood was analyzed for heavy metals (arsenic,

Table 1 Interpretation of mass spectra in Fig. 4 including proposed nominal molecular weights (mw) and lowest mass of principal high mw triplets relative to the presence of multiple chlorine atoms

\begin{tabular}{|c|c|c|c|c|c|c|c|c|c|c|}
\hline \multirow{2}{*}{$\begin{array}{l}\text { Mass } \\
\text { spectrum }\end{array}$} & \multirow{2}{*}{$\begin{array}{l}\text { Proposed } \\
\text { nominal mw }\end{array}$} & \multicolumn{5}{|l|}{ Loss } & \multirow{2}{*}{$\begin{array}{l}\text { Central } \\
\text { group }\end{array}$} & \multirow[t]{2}{*}{ Side arm $(A)$} & \multirow[t]{2}{*}{ Side arm $(B)$} & \multirow[t]{2}{*}{$A / B$} \\
\hline & & $\begin{array}{l}-\mathrm{CH}_{2} \mathrm{Cl} \\
\text { and }-\mathrm{CH}_{3} \\
\text { Lowest mas }\end{array}$ & $\begin{array}{l}-\mathrm{CH}_{2} \mathrm{Cl} \\
\text { of princip }\end{array}$ & $-\mathrm{Cl}$ & $\begin{array}{c}-\mathrm{CH}_{2} \\
\mathrm{mw} \text { triplet }\end{array}$ & $\mathrm{M}+$ & & & & \\
\hline A & 284 & & 235 & 249 & & & $\mathrm{PO}_{4}$ & $\mathrm{CH}_{2} \mathrm{CH}_{2} \mathrm{Cl}$ & & $3: 0$ \\
\hline B & 326 & & 277 & 291 & 311 & 325 & $\mathrm{PO}_{4}$ & $\mathrm{CH}\left(\mathrm{CH}_{3}\right) \mathrm{CH}_{2} \mathrm{Cl}$ & & $3: 0$ \\
\hline $\mathrm{C}$ & 326 & & 277 & 291 & 311 & 325 & $\mathrm{PO}_{4}$ & $\mathrm{CH}_{2} \mathrm{CH}_{2} \mathrm{CH}_{2} \mathrm{Cl}$ & & $3: 0$ \\
\hline $\mathrm{D}$ & 326 & & 277 & 291 & $<311>$ & $<325>$ & $\mathrm{PO}_{4}$ & $\mathrm{CH}\left(\mathrm{CH}_{3}\right) \mathrm{CH}_{2} \mathrm{Cl}$ & $\mathrm{CH}_{2} \mathrm{CH}_{2} \mathrm{CH}_{2} \mathrm{Cl}$ & $1: 2$ \\
\hline $\mathrm{E}$ & 370 & & 321 & 335 & & & $\mathrm{PO}_{4}$ & $\mathrm{CH}\left(\mathrm{CH}_{3}\right) \mathrm{CH}_{2} \mathrm{Cl}$ & $\mathrm{CH}\left(\mathrm{CH}_{2} \mathrm{Cl}\right)(\mathrm{C} \equiv \mathrm{CCl})$ & $2: 1$ \\
\hline $\mathrm{F}$ & 314 & 249 & & 279 & & & $\mathrm{~S}=\mathrm{PO}_{3}$ & $\mathrm{CH}_{2} \mathrm{CH}_{2} \mathrm{Cl}$ & $\mathrm{CH}_{2} \mathrm{CH}_{2} \mathrm{Cl}$ & $1: 2$ \\
\hline G & 329 & 249 & 279 & 293 & & & $\mathrm{PO}_{4}$ & $\mathrm{CH}_{2} \mathrm{CH}_{2} \mathrm{Cl}$ & $\mathrm{CH}_{2} \mathrm{CH}_{2} \mathrm{OCH}_{2} \mathrm{CH}_{2} \mathrm{Cl}$ & $2: 1$ \\
\hline
\end{tabular}

Data in italics have $\mathrm{Cl}_{3}$ pattern; the rest have $\mathrm{Cl}_{2}$ pattern. Data in curly brackets indicate low-intensity peaks, inferred from library match. The right side of the table indicates the proposed structural components for each compound. Compounds A-D and $\mathrm{G}$ are supported by matches to mass spectral library entries 
cadmium, lead, mercury, selenium, and thallium) by ICP/MS, and for cyanide [27]. Anticoagulant rodenticide testing was performed on whole blood samples by high-performance liquid chromatography (HPLC) [28]. Finally, liver samples were also tested for anticoagulant rodenticides using the same HPLC method [28].

The stomach content trace element and heavy metal profiles were normal, and samples also tested negative for cyanide and ethylene glycol. Whole blood tested positive for lead, but within normal ranges $(<50 \mathrm{ppb})$. No other heavy metals were found. Severe blood clotting in the sample prevented analysis for cyanide as DCPAH standard operating procedures require use of anticoagulated blood for this test. Anticoagulant rodenticide compounds tested negative in blood and liver samples in the DCPAH routine panel.

Results of the GC/MS analysis of stomach contents revealed a mixture of flame retardants and two UV absorbers (UVA), which were identified by matching to GC/MS NIST, Wiley, and in-house mass spectral libraries comprising over 520,000 spectra. The identified flame retardant compounds included TCEP, TCPP, bis(1-chloro2-propyl)-(3-chloro-1-propyl) phosphate, and its isomer bis (3-chloro-1-propyl)(1-chloro-2-propyl) phosphate. The peak areas of these compounds significantly exceeded that of the unlabeled $2 \mu \mathrm{g} / \mathrm{ml}$ internal standard at $13-\mathrm{min}$ retention time, implying their presence at concentrations likely exceeding $2 \mu \mathrm{g} / \mathrm{ml}$. The two UVA components present were bumetrizole and oxybenzone. The total ion chromatogram is shown in Fig. 3 (top). Selected ion chromatography focused on specific fragments and their isotopic profiles reflective of chlorination, i.e., mass spectral peaks separated by 2 amu and showing relative abundances of approximately $100 \%, 64 \%$, and $10 \%$ for dichlorinated species and $100 \%$, $95 \%$, and $31 \%$ for trichlorinated species. With this focus on such triplet $\mathrm{m} / \mathrm{z}$ values, ion chromatography for ions $\mathrm{m} / \mathrm{z} 249$, 251, and 253 (Fig. 3, middle) clearly revealed the TCEP peak at $13.50 \mathrm{~min}$ plus a series of related peaks between 13.70 and 17.00 min. Further ion chromatography (Fig. 3, bottom) for $m / z 277,279,281$, and 291 revealed the identified tris(1-chloro-2-propyl)phosphate, bis(1-chloro-2propyl)-(3-chloro-1-propyl) phosphate, and bis(3-chloro-1propyl)(1-chloro-2-propyl) phosphate as well as three additional compounds. The mass spectra for all seven related compounds are shown in Fig. 4, including the unidentified peaks e and $\mathrm{f}$, corresponding to retention times 14.75 and $16.55 \mathrm{~min}$, and an additional match to bis(2-chloroethyl)-2(2-chloroethoxy)-ethyl phosphate at $16.85 \mathrm{~min}$.

Analysis of the remaining spectra had a goal of assigning structures to unknowns e and f. Methods included ascertaining whether the highest molecular weight triplets represented burdens of two, three, or even more chlorine atoms from isotopic ratios, studying the pattern of fragmentations and inferring the likely molecular weight and structure that would accommodate all the data, and comparison with published spectra. The results of this analysis are shown in Table 1, listing the mass spectra designated $\mathrm{A}-\mathrm{G}$, their proposed molecular weights (A-D and $G$ are verified by their mass spectral matches), the lowest masses of chlorine-derived triplets spaced $+2 \mathrm{amu}$ apart, and across the top the mass spectral fragmentations that would account for the respective ion values. On the right side of the table are the summaries of all proposed structures, including whether the central group is a phosphate or phosphorothioate, what the side group(s) must be, and what the stoichiometry of those side groups must be when more than one type of side group is present. Surprisingly, compound F must be a phosphorothioate in order to interpret the data accurately; note that the literature supports the use of such compounds in flame retardant composition $[29,30]$. Note also that while generally not as potent as their organophosphate analogs [31], phosphorothioate-containing compounds can impose significant cholinesterase inhibition once converted to their oxon forms by oxidative desulfuration [31, 32].

\section{Discussion}

Organophosphate esters, in particular triesters such as TCEP and TCPP, are currently the most commonly used flame retardants in plastics, polymeric foams, synthetic fibers, and other materials $[2,7]$. TCEP is a colorless to pale yellow liquid, which is readily absorbed through the oral route and distributed to various organs, particularly liver, kidney, and brain. Metabolites in rats and mice include bis(2-chloroethyl) carboxymethyl phosphate, bis(2-chloroethyl)hydrogen phosphate, and bis(2-chloroethyl)-2-hydroxyethyl phosphate glucuronide [24]. Excretion is rapid, mainly through urine [33]. The acute oral $\mathrm{LD}_{50}$ for TCEP is reported to be in the range of $0.5-1.41 \mathrm{~g} / \mathrm{kg}$ body weight (bw) in rats [24]. Single-dose oral administration of $275 \mathrm{mg} / \mathrm{kg}$ bw of TCEP induced epileptiform convulsions and extensive loss of pyramidal cells in the CA1 region of the hippocampus in female rats [22]. The seizure-related and neurohistopathological effects of TCEP were significantly attenuated by pretreatment with atropine or chlordiazepoxide, suggesting that the hippocampal damage was related to the seizures produced by TCEP [22]. In a second study, rats gavaged with $275 \mathrm{mg} / \mathrm{kg}$ bw TCEP had impaired performance in the Morris water maze 3 weeks after administration, suggesting long-term impairment of some brain functions such as memory [22].

The structures of chemicals identified during the course of this work are listed in Table 2. The seizures reported for the dogs in case no. 1 are consistent with the findings of TCEP-induced acute toxicity. Ingestion of large amounts of TCEP embedded in foam is likely to have induced the 
Fig. 3 Case no. 2 stomach contents chromatography. Top, total ion chromatography, indicating major components of interest; middle, ion chromatography for $m / z 249,251$, and 253 revealed tris(2-chloroethyl) phosphate and structurally related peaks between 13.7 and $17.0 \mathrm{~min}$; bottom, ion chromatography for $m / z 277,279,281$, and 291 led to the identifications of four flame retardant components (two already labeled in top chromatogram) and two likely candidate structures labeled 370 and $314 \mathrm{mw}$ phosphates
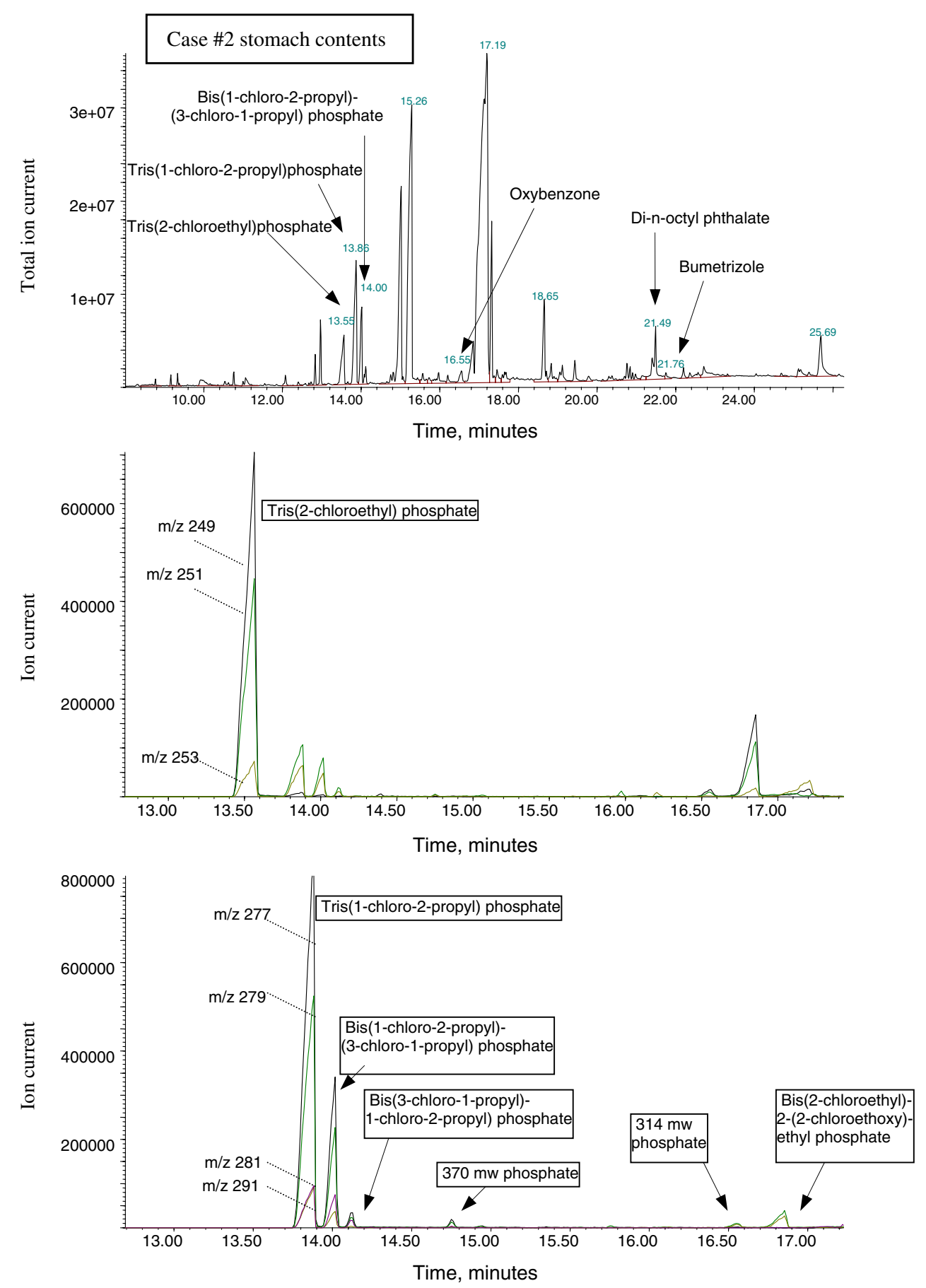

seizures. Because TCEP is an organophosphate ester (cf. Fig. 5 for comparison with other organophosphate compounds) and easily dissolves in numerous organic solvents, it likely crosses the blood-brain barrier [23]. Nonetheless, the mechanisms underlying TCEP neurotoxicity are not well known. It is reported to be a weak inhibitor of the acetylcholinesterase (ChE) and of the neuropathy target esterase (NTE) enzyme activities [34, 35]. However, when very large doses (14.2 g/kg bw) were given to hens, significant inhibition of plasma ChE (87.1\%) and NTE
(30\%) were observed $24 \mathrm{~h}$ after treatment [36]. We infer that TCEP caused neurotoxicity in these dogs, particularly since no other toxic compounds were identified in case report no. 1, and this same compound was present in case report no. 2, where it may have been the cause of acute death. In both cases, large amounts of this compound were found in stomach contents. It is important to point out that there is no information on the sensitivity of different animal species to TCEP and related organophosphate ester flame retardants. The rapid progression of clinical signs in these two case reports suggests that dogs 


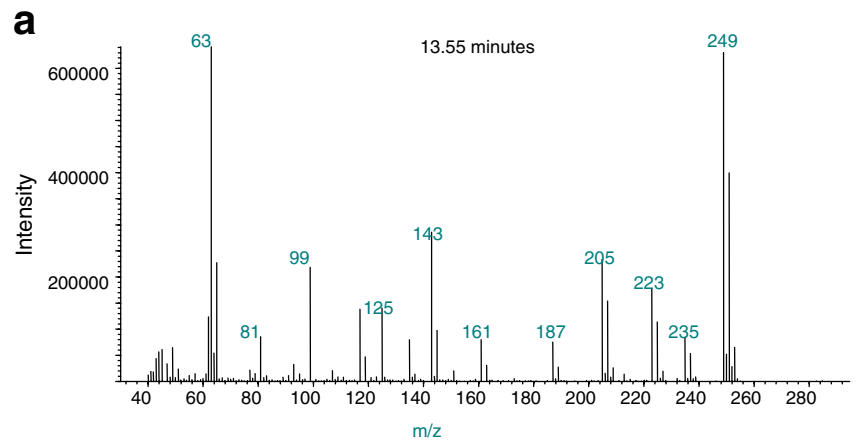

\section{b}

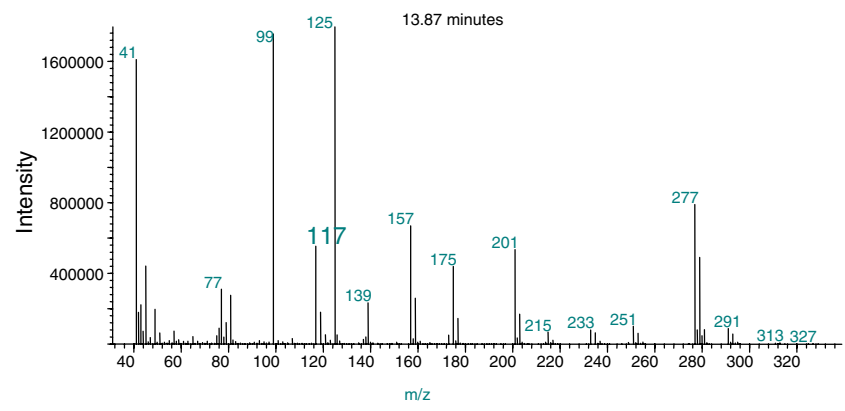

C
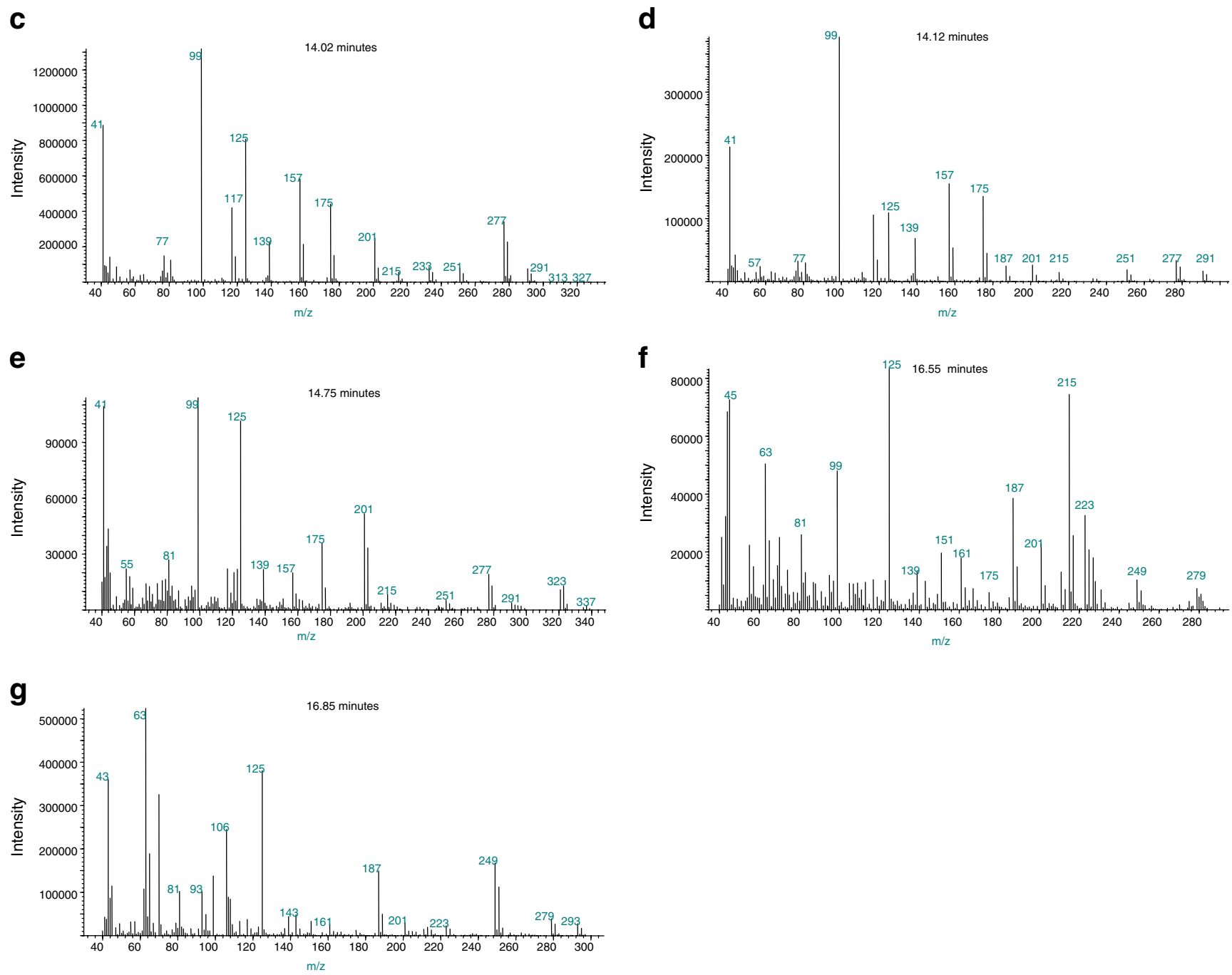

Fig. 4 Mass spectra of the flame retardant group and identified in case no. 2; highest visible mass triplet and library-confirmed identifications are indicated as follows: a tris(2-chloroethyl)phosphate, mw 284 (CAS no. 115-96-8; $\mathrm{m} / \mathrm{z} 249,251$, and 253); b tris(2chloroisopropyl)phosphate, mw 327 (CAS no. 13674-84-5; $\mathrm{m} / \mathrm{z} 325$, 327, and 329); c bis(1-chloro-2-propyl)(3-chloro-1-propyl)phosphate,

may be more sensitive to the acute toxic effects of these compounds compared with rats or chicken.

The mechanisms involved in the epileptiform convulsions seen in case report no. 1 are likely related to antagonistic effects

$327 \mathrm{mw}$ (CAS no. 137909-40-1; $\mathrm{m} / \mathrm{z} 311,313$, and 315 plus 325, 327, and 329); d bis(3-chloro-1-propyl)(1-chloro-2-propyl)phosphate, mw 327 (CAS no. 137888-35-8; m/z 291, 293, and 295); e $370 \mathrm{mw}$, $\mathrm{m} / \mathrm{z} 335,337$, and 339; f $314 \mathrm{mw}, \mathrm{m} / \mathrm{z} 279,281$, and 283; $\mathbf{g}$ bis(2chloroethyl)-2-(2-chloroethoxy)ethyl phosphate, mw 328 (CAS no. 137888-36-9; $\mathrm{m} / \mathrm{z} 293,295$, and 297)

of TCEP to gamma-amino butyric acid (GABA). Single administration of $200 \mathrm{mg} / \mathrm{kg}$ bw of TCEP was shown in one study to increase the ambulatory activity (AA) in male ICR strain mice [23]. In order to examine the neurochemical 
Table 2 Flame retardant compounds mentioned in the accompanying case reports

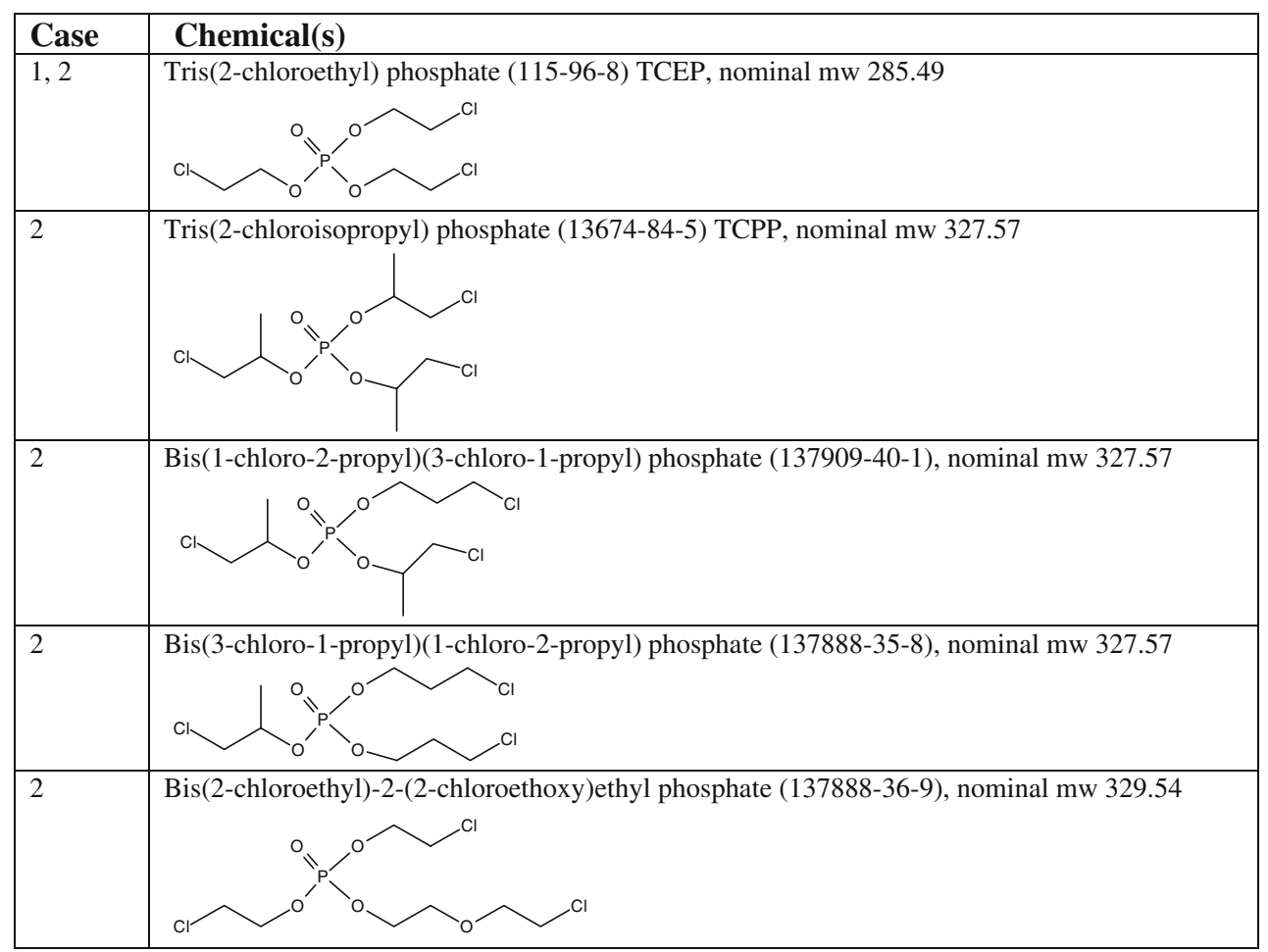

mechanisms implicated in this effect, TCEP was administered together with various psychoactive drugs. When given together with mecamylamine (nicotinic cholinergic antagonist) or scopolamine (muscarinic cholinergic antagonist), the AA response was not affected. On the other hand, the benzodiazepine agonist diazepam, and the $\mathrm{GABA}_{\mathrm{A}}$ agonists muscimol and baclofen, all attenuated the effects of TCEP, suggesting that TCEP acts as a GABA antagonist. GABA is one of the

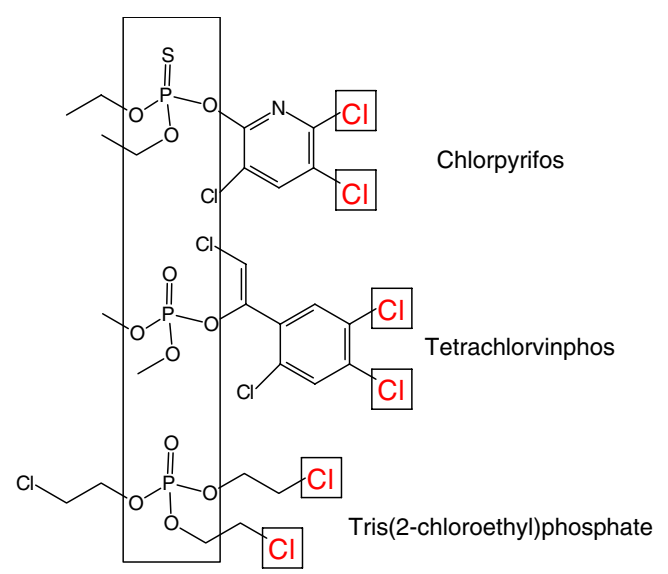

Fig. 5 Comparison of organophosphate insecticides [top and middle] with flame retardant TCEP [bottom]. Structural features in common include the central phosphate or phosporothioate group as well as multiple chlorine atoms. Note that chlorpyrifos and tetrachlorvinphos are known to have cholinesterase inhibition properties [50-52], whereas the mechanisms involved in TCEP neuropathology are not definitively known at present major inhibitory neurotransmitters in the mammalian CNS, which regulates neuronal excitability, mainly by regulation of synaptic inhibition in the adult brain. Inhibition of GABA can lead to seizures, and GABA receptor antagonists have been used to induce epileptic seizures in experimental animals such as rats $[37,38]$.

Short-term studies regarding TCEP exposure found increases in mean absolute and relative kidney weights as well as relative liver weights [24]. The necropsy report in case no. 2 revealed dark-colored congested liver and kidneys. Unfortunately, no formalin-fixed samples were saved for histological assessment of potential toxicity of TCEP to these organs. However, TCEP induced toxicity to these organs, including lesions in renal proximal convoluted tubules of the inner cortex and the outer strip of the outer medulla in rats, has been documented in the literature [24, $25,35]$. Still, the mechanisms involved in hepato- and nephrotoxicity remain unclear. CNS lesions have also been described for TCEP, including hippocampal lesions; degenerative lesions of the thalamus, hypothalamus, and basal ganglia; and neuronal necrosis [24].

TCPP was an additional compound identified by GC/MS in case report no. 2. TCPP is a colorless liquid used as flame retardant, mainly in polyurethane foams. Elimination is by urinary and fecal routes in rats, with urinary excretion being identified as the primary route [39]. In one study, $89 \%$ of the dose was eliminated in $72 \mathrm{~h}$ via urine [40]. Acute toxicity by the oral route is reported to be low to 
moderate, with an $\mathrm{LD}_{50}$ value in rats in the range of 1,017 $4,200 \mathrm{mg} / \mathrm{kg}$ bw [24]. Groups of rats exposed to different levels of TCPP in feed revealed no treatment-related changes in hematology, clinical chemistry, or acetylcholinesterase enzyme activity. Increased relative and absolute liver weights were reported, with no concomitant histopathological findings [24]. This indicates that TCPP is likely less toxic than TCEP, and the acute toxicity seen in case report no. 2 is likely caused primarily by TCEP. Potential interaction between the two compounds cannot be ruled out, however. The authors are not aware of combined toxicity studies of TCEP and TCPP in animals. The possibility of potentiation or synergistic interaction resulting in enhanced toxicity exists in these cases.

Regarding the other principal compounds present in case report no. 2, bis(1-chloro-2-propyl)-(3-chloro-1-propyl) phosphate and its isomer bis(3-chloro-1-propyl)(1-chloro2-propyl) phosphate, few data were found in the literature. TCPP is manufactured to a purity of $75-100 \%$ in commercial preparations, as are related chlorinated phosphate esters [41]. Major impurities for TCPP are listed as bis(1-chloro-2-propyl)(2-chloro-1-propyl) phosphate (CAS no. 76025-08-6; 20-30\%) and bis(2-chloro-1-propyl)(1chloro-2-propyl) phosphate (CAS no. 76649-15-5; 3-5\%) [41]. The potential contribution of all these compounds to the clinical signs reported in case report no. 2 is unclear. Regarding the UVA compounds found in the stomach contents, i.e., bumetrizole and oxybenzone, they are known to be of low toxicity and again are unlikely to have contributed to toxicity in case report no. 2 [42].

As dogs in case report no. 2 were left enclosed in a vehicle, the possibility that heat stroke was a factor [26] cannot be ruled out. However, the likelihood of heat stroke is minimized because the dogs were left locked in the car sometime after $11 \mathrm{PM}$ and were found dead at $9 \mathrm{AM}$ the following day during the month of June in a Midwestern State. The upper lethal body temperature in dogs is $107.6^{\circ} \mathrm{F}$ and is unlikely to be reached at such hours of the night. Temperatures ranged from $71^{\circ} \mathrm{F}$ to $77^{\circ} \mathrm{F}\left(21-25^{\circ} \mathrm{C}\right)$ with no severe weather recorded at a nearby airport and retrievable from archives of the National Oceanic and Atmospheric Administration (http://www7.ncdc.noaa.gov/IPS/coop/ coop.html). Instead, the striking similarity in toxicological findings between the two case reports persuaded us to believe that they are causally related, especially the presence of large amounts of seat foam in the stomach. Heat exhaustion was clearly not a factor in case report no. 1 .

The possibility of gastrointestinal obstruction was raised during review of this paper. Such obstruction was ruled out as a differential as no signs of obstruction were noticed at necropsy.

The likelihood that flame retardants, in particular TCEP, were the primary cause of death in case report no. 2 is strengthened by the following considerations: (1) both cases 1 and 2 involved likely differentials of acute toxicity, and despite extensive examination, only flame retardants were found; (2) heat stroke was raised as a possibility in case 2 , but the atmospheric conditions do not strongly support this differential; (3) finally, a review of the international patent literature reveals that the majority of manufactured polyurethane foams contain TCEP (or other flame retardants) in the range of $5-10 \%$ by weight, with exceptional patents describing as little as $1 \%$ or as much as $30 \%$ embedded TCEP [43-49]. At 5\% TCEP, or $50,000 \mathrm{mg} / \mathrm{kg}$, and given an acute oral LD50 of as little as $0.5 \mathrm{~g} / \mathrm{kg}$ body weight, a $25 \mathrm{~kg}$ animal would only have to ingest $250 \mathrm{~g}$ of foam to reach the low end of the LD50 range. This appears to be readily achievable given the large visible chunks of seat cushion material observed in stomach contents at necropsy.

In conclusion, the chlorinated organophosphate triesters such as TCEP and TCPP are used as FRs, are employed in consumer articles for indoor use such as foams and thus are nearly ubiquitous [2]. Despite their widespread use, the toxic effects of these compounds in animals and people are not well known. This is the first report linking acute deaths in dogs with ingestion of car seat cushions found to contain large amounts of TCEP, the likely most significant toxicant. These compounds induce epileptiform seizures probably by inhibiting GABA in the central nervous system. Uncontrolled seizure activity is likely the cause of death in these dogs. Potential interaction among the different compounds found in case 2 remains a possibility. More work remains to be done to determine the potential neurotoxicity of these compounds in pet animals and humans given their widespread use in home environments.

Acknowledgements The authors would like to thank Dr. Ray Hostetter, DVM, and Dr. Russel Seifferlein, DVM, for the information and the data provided on case reports no. 1 and 2, respectively.

\section{References}

1. International Program on Chemical Safety (IPCS) (1997) Environmental Health Criteria no. 192. Flame retardants: a general introduction. World Health Organization, Geneva

2. Reemtsma T, Quintana JB, Rodil R, García-López M, Rodríguez I (2008) Organophosphorus flame retardants and plasticizers in water and air. I. Occurrence and fate. Trends Analyt Chem 27:727-737

3. Hardy ML (2002) The toxicology of the three commercial polybrominated diphenyl oxide (ether) flame retardants. Chemosphere 46:757-777

4. Mikula P, Svóbodova Z (2006) Brominated flame retardants in the environment: their sources and effects (a review). Acta Vet Brno 75:587-599

5. Darnerud PO, Eriksen GS, Jóhannesson T, Larsen PB, Viluksela M (2001) Polybrominated diphenyl ethers: occurrence, dietary 
exposure, and toxicology. Environ Health Perspect 109 (Suppl 1):49-68

6. Darnerud PO (2003) Toxic effects of brominated flame retardants in man and in wildlife. Environ Int 29:841-853

7. Marklund A, Andersson B, Haglund P (2003) Screening of organophosphorus compounds and their distribution in various indoor environments. Chemosphere 53:1137-1146

8. García-López M, Rodrígueza I, Celaa R, Kroening KK, Caruso JA (2009) Determination of organophosphate flame retardants and plasticizers in sediment samples using microwave-assisted extraction and gas chromatography with inductively coupled plasma mass spectrometry. Talanta 79:824-829

9. Sakamoto T, Sawada Y, Nishide K, Sadamitsu D, Yoshioka T, Sugimoto T, Nishii S, Kishi H (1984) Delayed neurotoxicity produced by an organophosphorous compound (Sumithion). Arch Toxicol 56:136-138, Including comments by Chuecos JM, Violan JS. Arch. Toxicol. 1985; 58:123-124 and Sakamoto T, Arch. Toxicol. 58:124

10. Valvassori SS, Fortunato JJ, Gomes KM, Reus GZ, Martins MR, Gavioli EC, Schetinger MRC, Dal-Pizzol F, Quevedo J (2007) Acute and subacute exposure to malathion impairs aversive but not non-associative memory in rats. Neurotox Res 12:71-80

11. Schmidt G, Gruetzmacher J (1969) Late effects on respiration and circulation following successful treatment of Para-oxon (organophosphate) poisoning with cholinesterase reactivators and atropine in cats. Archiv fuer Toxikologie 24:102-122

12. Lee J-C, Lin K-L, Lin J-J, Hsia S-H, Wu C-T (2010) Nonaccidental chlorpyrifos poisoning - an unusual cause of profound unconsciousness. Eur J Pediatr 169:509-511

13. Sheftel VO (2000) Indirect food additives and polymers. Migration and toxicology. Lewis, Boca Raton, p 220

14. Lefaux R (1968) Practical toxicology of plastics. CRC, Cleveland, p 336

15. Laham S, Long G, Schrader K, Szabo J (1984) Induction of electrophysiological and morphological changes in SpragueDawley rats fed tributoxyethyl phosphate. J Appl Toxicol 4:42-48

16. Saitoh M, Umemura T, Kawasaki Y, Momma J, Matusuhima Y, Matusumoto M et al (1994) Subchronic toxicity study of tributoxyethyl phosphate in Wistar rats. Bull Natl Inst Hyg Sci 112:27-39

17. Carrington CD, Lapadula DM, Othman M, Farr C, Nair RS, Johannse F et al (1996) Assessment of the delayed neurotoxicity of tributyl phosphate, tributoxyethyl phosphate and dibutylphenyl phosphate. Int J Occup Med Tox 5:61-68

18. Sato T, Watanabe K, Nagase H, Kito H, Niikawa M, Yoshioka Y (1997) Investigation of the hemolytic effects of various organophosphoric acid triesters (OPEs) and their structure-activity relationship. Toxicol Environ Chem 59:305-313

19. Laham S, Broxup BR, Long GW (1985) Subchronic oral toxicity of tributoxyethyl phosphate in the Sprague-Dawley rat. Arch Environ Health 40:12-17

20. Ingerowski G, Firedle A, Thumulla J (2001) Chlorinated ethyl and isopropyl phosphoric acid triesters in the indoor environment - an interlaboratory exposure study. Indoor Air 11:145-149

21. Hartmann PC, Bürgi D, Giger W (2004) Organophosphate flame retardants and plasticizers in indoor air. Chemospher 57:781-787

22. Tilson HA, Veronesi B, McLamb RL, Matthews HB (1990) Acute exposure to tris(2-chloroethyl)phosphate produces hippocampal neuronal loss and impairs learning in rats. Toxicol Appl Pharmacol 106:254-269

23. Umezu T, Yonemoto J, Soma Y, Susuki T (1998) Tris(2chloroethyl)phosphate increases ambulatory activity in mice: pharmacological analyses of its neurochemical mechanism. Toxicol Appl Pharmacol 148:109-116

24. International Program on Chemical Safety (IPCS) (1998) Environmental Health Criteria no. 209. Flame retardants: tris(chlor- opropyl) phosphate and tris(2-chloroethyl) phosphate. World Health Organization, Geneva

25. Hughes MF, Edwards BC, Mitchell CT, Bhooshan B (2001) In vitro dermal absorption of flame retardant chemicals. Food Chem Toxicol 39:1263-1270

26. Gregory NG, Constantine E (1996) Hyperthermia in dogs left in cars. Vet Rec 139:349-350

27. Rieders F (1975) Cyanides: type B procedure. In: Sunshine I (ed) Methodology for analytical toxicology. CRC, West Palm Beach, pp $120-122$

28. Reynolds JD (1980) Extraction and identification of ten anticoagulant rodenticides from baits and stomach contents by high pressure liquid chromatography. Proc Annu Meet Am Assoc Vet Lab Diag 23:187-194

29. Anderson JJ, Byrd WM, Jr., Camacho VG (1970) Phosphorothioates and their use in flame-retardant polymeric material. Ger. Offen. 59pp. Patent \# DE 2024392 19701126. Patent written in German

30. Mikhailov M, Stoeva S (1978) Preparation of tris(beta, beta', beta"-chloroethyl)phosphite and its use as a plasticizer and stabilizer of poly(vinyl chloride). Godishnik Visshiya Khimiko Tekhnologichen Inst Burgas 12:133-140

31. Sanchez-Hernandez, Walker $\mathrm{CH}$ (2000) In vitro and in vivo cholinesterase inhibition in lacertides by phosphonate- and phosphorothioate-type organophosphates. Pesticide Biochem Physiol 67:1-12

32. Amitai G, Moorad D, Adani R, Doctor BP (1998) Inhibition of acetylcholinesterase and butyrylcholinesterase by chlorpyrifosoxon. Biochem Pharmacol 56:293-299

33. Burka LT, Sanders JM, Herr DW, Mathews HB (1991) Metabolism of tris(2-chloroethyl)phosphate in rat and mice. Drug Metab Dispos 19:443-447

34. Eldefrawi AT, Mansour NA, Brattsten LB, Ahrens VD, Lisk DJ (1977) Further toxicological studies with commercial and candidate flame retardant chemicals. Part II Bull Environ Contam Toxicol 17:720-726

35. Matthews HB, Dixon D, Herr DW, Tilson H (1990) Subchronic toxicity studies indicate that tris(2-chloroethyl) phosphate administration results in lesions in the rat hippocampus. Toxicol Ind Health 1:1-15

36. Sprague GL, Sandvik LL, Brookins-Hendricks MJ, Bickford AA (1981) Neurotoxicity of two organophosphorus ester flame retardants in hens. J Toxicol Environ Health 8:507-518

37. Ben-Ari Y (2002) Excitatory actions of GABA during development: the nature of the nurture. Nat Rev Neurosci 3:728-739

38. Rogawski MA, Loscher W (2004) The neurobiology of antiepileptic drugs. Nat Rev Neurosci 5:553-564

39. Minegishi K, Kurebayashi H, Nambaru S, Morimoto K, Takahashi T, Yamaha T (1988) Comparative studies on absorption, distribution, and excretion of halogenated alkyl phosphate flame retardants in rats. Eisei Kagaku 34:102-114

40. Föllmann W, Wober J (2006) Investigation of cytotoxic, genotoxic, mutagenic, and estrogenic effects of the flame retardants tris-(2-chloroethyl)-phosphate (TCEP) and tris-(2-chloropropyl)phosphate (TCPP) in vitro. Toxicol Lett 161:124-134

41. United Nations Environment Programme (2005 ) International Programme on Chemical Safety Monograph [webpage on the Internet]. Tris(1-chloro-2-propyl)phosphate CAS No. 13674-84-5. United Nations Environment Programme, Geneva. http://www. inchem.org/documents/sids/sids/13674845.pdf

42. Himmelsbach M, Buchberger W, Reingruber E (2009) Determination of polymer additives by liquid chromatography coupled with mass spectrometry. A comparison of atmospheric pressure photoionization (APPI), atmospheric pressure chemical ionization (APCI), and electrospray ionization (ESI). Polym Degrad Stab 94:1213-1219 
43. Stimberg HJ, Galinke J, Gruenberger E (1970) Polyurethane foam. (Henkel und Cie. G.m.b.H.). Ger. Offen. 11 pp. Patent \# DE 1800460. Patent written in German

44. Anonymous (1971) Self-extinguishable rigid foams based on polyurethanes and addition compounds of urea and formaldehyde. (Crediplast). Fr. 14 pp. Patent \# FR 2051948 Patent written in French

45. Iordanskaya OA, Shoshtaeva MV, Turetskii LV, Kalinin BA (1979) Rigid polyurethane foam compositions. (USSR). U.S.S.R. Patent \# SU 64232719790115 Patent written in Russian

46. Anonymous (1979) Improvements in or relating to the production of polyurethane foam. (Tenneco Chemicals, Inc., USA). Brit. 11 pp. Patent \# GB 154670519790531 Patent written in English

47. Kennedy RB. Polyurethane foams. (USA) (1983) PCT Int. Appl. 29 pp. Patent \# WO 8302120. Patent written in English
48. Yasui S, Nagata K (1985) Polyurethane foams. (Sanyo Chemical Industries Ltd., Japan). Jpn. Kokai Tokkyo Koho. 8 pp. Patent \# JP 60133020. Patent written in Japanese

49. Buchanan MS, Davis GB, Greenhouse WVV (1989) Polyurethane foams containing organofunctional silanes. (William T. Burnett and Co., Inc., USA). U.S. 7 pp. Patent \# US 4839393. Patent written in English

50. Wurpel JN, Hirt PC, Bidanset JH (1993) Amygdala kindling in immature rats: proconvulsant effect of the organophosphate insecticide-chlorpyrifos. Neurotoxicology 14:429-436

51. Karanth S, Pope C (2003) In vitro inhibition of blood cholinesterase activities from horse, cow, and rat by tetrachlorvinphos. Int J Toxicol 22:429-433

52. Gromysz-Kałkowska K, Szubartowska EL (1993) Toxicity of tetrachlorvinphos to Rana temporaria L. Comp Biochem Physiol C 105:285-290 